\title{
Carbohydrate loading in practice: high muscle glycogen concentration is not certain
}

\author{
G. M. Fogelholm MSc ${ }^{1}$, H. O. Tikkanen $\mathrm{MD}^{2}$, H. K. Näveri MD, $\mathrm{PhD}^{3}$, L. S. Näveri $\mathrm{MD}^{2}$ \\ and $M$. H. A. Härkönen $\mathrm{MD}^{4}$
}

${ }^{1}$ Department of Nutrition, University of Helsinki, Finland

${ }^{2}$ Department of Clinical Chemistry, University of Helsinki, Finland

${ }^{3}$ First Department of Medicine, University of Helsinki, Finland

${ }^{4}$ Professor of Clinical Chemistry, University of Helsinki, Finland

It is believed that muscle glycogen resynthesis can be stimulated by depleting the glycogen stores by heavy physical exercise and then eating a diet rich in carbohydrates. In this study, we compared muscle glycogen concentrations after two different depletion and loading procedures in six male runners. The depletion runs for the procedures were a half-marathon race and an easier fartlek. The mean muscle glycogen concentrations ( \pm s.e.m.), analysed after the procedures, did not differ significantly between the race and the fartlek being 285 $( \pm 25) \mathrm{mmol} / \mathrm{kg}$ d.w. (dry weight) versus 315 ( \pm 32$)$ $\mathrm{mmol} / \mathrm{kg}$ d.w. $(P>0.05)$. Moreover, the subjects' glycogen concentrations were not clearly increased above the predepletion values following either procedure. The results show that higher glycogen levels do not necessarily occur after classical carbohydrate-loading procedures.

Keywords: Carbohydrate diet, hormones, marathon

Studies in the late 1960 s showed a positive correlation between the pre-exercise muscle glycogen concentration and the ability to perform prolonged, severe exercises $^{1}$. An elevation of muscle glycogen stores can be achieved by a manipulation of the diet $t^{2-5}$. In the classical method ${ }^{2}$, muscle glycogen stores are first depleted by prolonged, exhaustive exercise, followed by 2-3 days of low-carbohydrate diet, i.e. fat and protein mainly. Then the stores are replenished by eating a high-carbohydrate diet and taking only light exercise.

The exhaustive depletion exercise has been criticized, because it interferes with the peaking for an important race ${ }^{6}$. Sherman and Costill ${ }^{4}$ and Blom et al. ${ }^{7}$ have shown that an exhaustive depletion brought about by running might even be totally ineffective in stimulating glycogen synthesis. Despite this, the traditional procedure (exhaustive depletion followed by a carbohydrate-rich diet) is carried out by many endurance athletes as a final preparation for a race.

The aim of the present study was to find out whether muscle glycogen concentrations would

Address for correspondence: G. M. Fogelholm, University of Helsinki, Department of Nutrition, SF-00710 Helsinki, Finland (C) 1991 Butterworth-Heinemann Ltd.

0306-3674/91/010041-04 differ after two dissimilar carbohydrate-loading procedures, performed in field conditions. The depletion exercises for the procedures involved: a halfmarathon race and an easier fartlek. Both procedures are commonly used by marathon runners.

We also investigated the extent of the physical strain caused by the two depletion runs. Changes in serum testosterone, free testosterone and cortisol concentrations are used as indicators of strain ${ }^{8}$. The rationale for measuring these hormones is that serum testosterone and free testosterone concentrations have been shown to decrease and serum cortisol concentrations to increase as a consequence of heavy physical exercise ${ }^{9,10}$.

\section{Subjects and methods \\ Subjects and experimental design}

After being informed of the experimental procedures and inherent risks, six well trained, national level, endurance runners (age $29( \pm 2)$ years, weight $66( \pm 2)$ $\mathrm{kg}$, height $171( \pm 1) \mathrm{cm}$ and training $552( \pm 35) \mathrm{km}$ during the previous month - all figures being mean ( \pm s.e.m.)) gave their written consent to participate in the study. Easy training, no more than $1 \mathrm{~h}$ per day, was allowed for the 3 days before the depletion run. The subjects performed two carbohydrate-loading procedures, but the depletion runs were different. Twenty-one days separated the two depletion runs, in order to avoid possible carry-over effects from the first procedure.

\section{Depletion and loading}

In the 'race' procedure, the depletion run involved a half-marathon road-race on relatively flat terrain. The subjects ran the distance in $74.2( \pm 0.5) \mathrm{min}$ and their running speed was $3.5 \mathrm{~min} / \mathrm{km}(4.8 \mathrm{~m} / \mathrm{s})$, roughly equivalent to $70-80 \%$ of their $\dot{V}_{\mathrm{O}_{2} \text { max }}$. The race was followed by maximal $200 \mathrm{~m}$ spurts until voluntary exhaustion occurred (about 15 spurts). Their total running time was $95-100 \mathrm{~min}$. In the 'fartlek' procedure the running course differed and it was not totally flat; the athletes' total running time was the same as for the race $(95-100 \mathrm{~min})$, but their mean 
Table 1. Experimental procedures

\begin{tabular}{|c|c|c|c|}
\hline \multicolumn{2}{|c|}{ Procedure 1: Race } & \multirow{2}{*}{$\begin{array}{l}\text { Procedure 2: Fartlek } \\
\text { Easy running } 60 \mathrm{~min}\end{array}$} & \multirow[t]{2}{*}{ Samples } \\
\hline Day-1 & Easy running $60 \mathrm{~min}$ & & \\
\hline \multicolumn{4}{|c|}{ Depletion } \\
\hline Day 0 & $\begin{array}{l}\text { Half-marathon race } \\
(3.5 \mathrm{~min} / \mathrm{km}) \text { and } \\
10-20 \times 200 \mathrm{~m} \text { until } \\
\text { exhaustion }\end{array}$ & $\begin{array}{l}100 \mathrm{~min} \text { running } \\
(4.0 \mathrm{~min} / \mathrm{km})\end{array}$ & $\mathrm{Bm}, \mathrm{M}$ \\
\hline Day 1 & Running 80-90 min & Running 80-90 min & $\mathrm{Fr}$ \\
\hline \multicolumn{4}{|c|}{ Loading } \\
\hline Day 2 & Easy running $45-60 \mathrm{~min}$ & Easy running $45-60 \mathrm{~min}$ & $\mathrm{Bm}$ \\
\hline Day 3 & Easy running $45-60 \mathrm{~min}$ & Easy running $45-60 \mathrm{~min}$ & $\mathrm{Fr}$ \\
\hline Day 4 & Easy running $45-60 \mathrm{~min}$ & Easy running $45-60 \mathrm{~min}$ & $\mathbf{F r}$ \\
\hline Day 5 & Easy running $45-60 \mathrm{~min}$ & Easy running $45-60 \mathrm{~min}$ & $\mathrm{Fr}$ \\
\hline Day 6 & Rest & Rest & $\mathrm{Bm}, \mathrm{M}$ \\
\hline
\end{tabular}

$\mathrm{Ba}$, post-run blood samples taken in the afternoon; Bm, fasting blood sample taken in the morning; $F r$, food record; $M$, muscle biopsy taken in the morning

running speed was slower $(4.0 \mathrm{~min} / \mathrm{km}$ or $4.2 \mathrm{~m} / \mathrm{s})$, close to their normal training pace.

On the first day after the depletion run, an $80-90 \mathrm{~min}$ run was executed. The subjects ate a reduced carbohydrate diet for these 2 days. During the 4-day carbohydrate-loading phase, the subjects executed one easy $45-60 \mathrm{~min}(4.5 \mathrm{~min} / \mathrm{km})$ run per day. The experimental procedures are shown in Table 1.

The athletes were instructed on how to choose foods and liquids that would ensure a reducedcarbohydrate diet during the depletion phase. More detailed instructions were provided for the highcarbohydrate diet. All subjects were instructed how to compose a basic diet ${ }^{11}$ that would ensure a daily carbohydrate intake of $400 \mathrm{~g}$. They were then able to choose from several different food items, providing additional carbohydrate. This was to make certain that they increased their daily intake of carbohydrate to $9 \mathrm{~g} / \mathrm{kg}$ body weight. The daily nutrient intake was calculated from the subjects' food diaries by a computer program ${ }^{12}$. To aid their food-recording process, all participants were given postal scales for weighing portions. During loading, there were no significant differences in the carbohydrate intake between the intense and moderate procedures (Table 2). The mean percentages of carbohydrate in the total energy intake were $70 \%$ for the race procedure and $67 \%$ for the fartlek.

Table 2. Energy and carbohydrate intake of six marathon runners during two carbohydrate-loading procedures. Results are expressed as mean ( \pm s.e.m.)

\begin{tabular}{lcc}
\hline & $\begin{array}{c}\text { Procedure 1: } \\
\text { Race }\end{array}$ & $\begin{array}{c}\text { Procedure 2: } \\
\text { Fartlek }\end{array}$ \\
\hline $\begin{array}{l}\text { Energy (MJ/day) } \\
\text { Depletion (days 0-1) } \\
\quad \text { Loading (days 2-5) }\end{array}$ & $9.2( \pm 1.1)$ & $7.9( \pm 0.8)$ \\
$\begin{array}{c}\text { Carbohydrates (g/day) } \\
\text { Depletion (days 0-1) } \\
\text { Loading (days 2-5) }\end{array}$ & $205( \pm 68)$ & $15.6( \pm 1.0)^{*}$ \\
\hline
\end{tabular}

* Significant difference $(P<0.05)$ between the procedures

\section{Blood analyses}

All blood samples were taken after a 15 min rest. The venous blood samples were drawn from the antecubital vein with the subjects in a sitting position. After an overnight fast, the morning samples were taken between 8.00 and 10.00 hours. Samples were also drawn within $1 \mathrm{~h}$ after each depletion run. Only water, in unlimited amounts, was allowed between the run and the time of taking the sample.

Radioimmunological methods were used for the measurement of serum cortisol and testosterone ${ }^{9}$. Serum sex hormone-binding globulin (SHBG) concentrations were determined by an immunoradiometric (IRMA) method (Farmos Diagnostica, Oulunsalo, Finland $)^{13}$. Serum free-testosterone concentrations were calculated using testosterone and SHBG values $^{14}$. All measurements were carried out in duplicate, and in order to avoid interassay variation, all the assays of each subject were run in the same series. The intra-assay coefficients of variation for the analyses were $9.1 \%$ for plasma cortisol, $8.3 \%$ for plasma testosterone and $8.8 \%$ for $\mathrm{SHBG}^{9}$.

\section{Muscle analyses}

After local anaesthesia of the skin with lignocaine, without adrenaline, muscle biopsies were taken from the lateral portion of the quadriceps femoris muscle. Because we had previously taken several consecutive biopsies from that muscle, without the subjects experiencing complications, the vastus lateralis was chosen as the biopsy site ${ }^{15}$. The muscle samples were taken before the depletion runs and at the end of the loading phase. The concentration of muscle glycogen was measured from 50-350 $\mu \mathrm{g}$ of freeze dried cryostat sections after alkaline digestion and ethanol precipitation $^{16}$. The samples were then analysed for glu$\operatorname{cose}^{17}$. The results are expressed in glycosyl units.

\section{Statistical analyses}

All results are expressed as mean ( \pm s.e.m.). Analysis of variance for repeated measurements (BMDP $2 \mathrm{~V}$-package) was used for the statistical analyses. Significant $(P<0.05)$ time, procedure or time $\times$ procedure effects were further identified by Wilcoxon's signed rank test ${ }^{18}$.

\section{Results}

Normal muscle glycogen concentrations were observed before both procedures: the group mean values were $343( \pm 10) \mathrm{mmol} / \mathrm{kg} \mathrm{d} . \mathrm{w}$. before the race procedure, and $345( \pm 11) \mathrm{mmol} / \mathrm{kg} \mathrm{d} . \mathrm{w}$. before the fartlek. There were no differences $(P>0.05)$ in glycogen concentrations resulting from the two carbohydrate-loading procedures (Figure 1): the range of post-loading muscle glycogen concentration was $170-350 \mathrm{mmol} / \mathrm{kg} \mathrm{d.w.} \mathrm{after} \mathrm{the} \mathrm{race,} \mathrm{and}$ $217-393 \mathrm{mmol} / \mathrm{kg} \mathrm{d} . \mathrm{w}$. after the fartlek. The two very low glycogen levels (one after the race, the other after the fartlek) were not found in the same subject. After a total of 12 depletion and loading procedures (two 

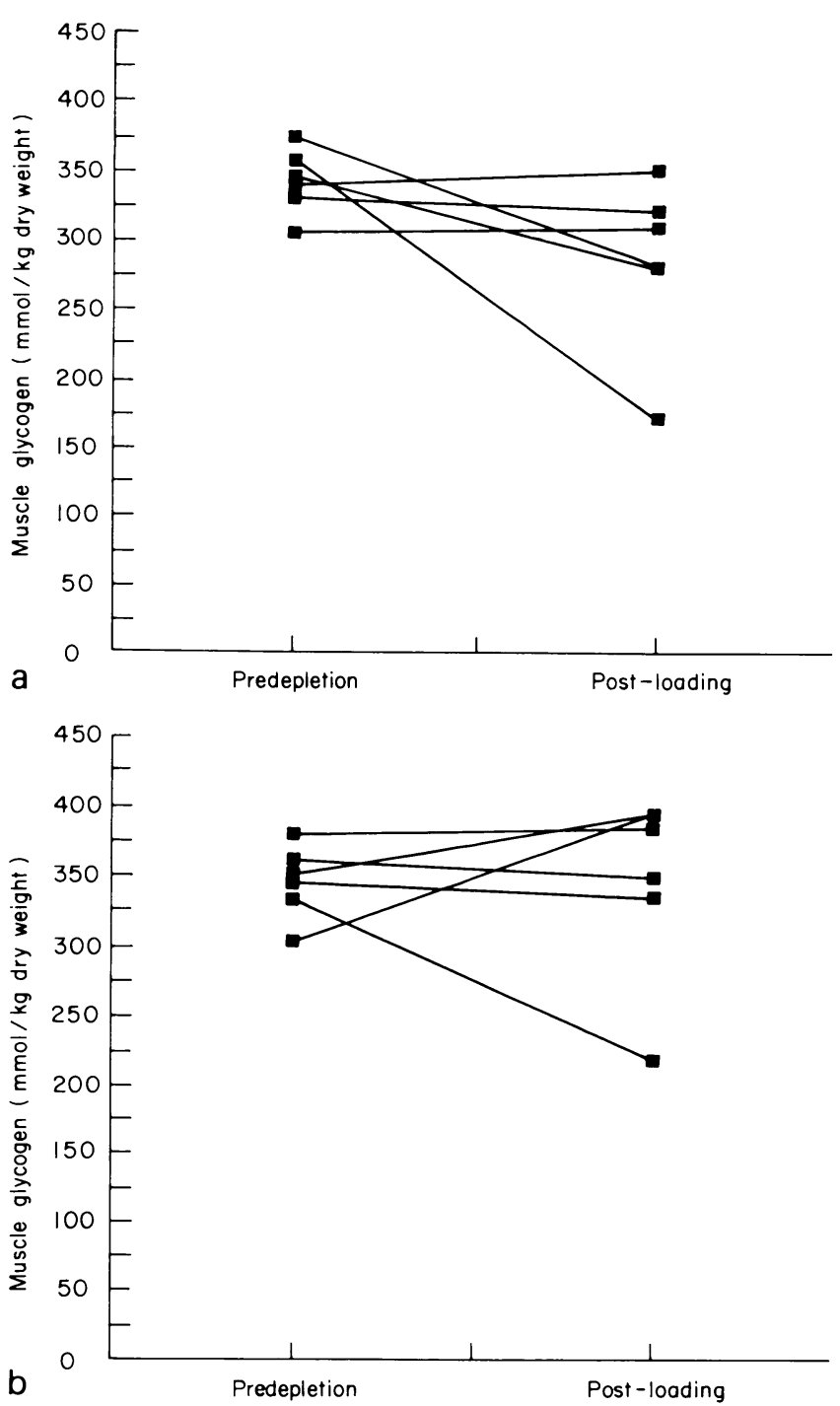

Figure 1. Individual changes of muscle glycogen concentrations in the lateral portion of the quadriceps muscle before and after two depletion and loading procedures performed by six male runners: $\mathbf{a}$ procedure 1 , race; $\mathbf{b}$ procedure 2, fartlek

for each subject) were carried out, only five resulted in increased glycogen levels.

A significant $(P<0.05)$ decrease in the serum free-testosterone concentrations (Figure 2) was observed after both depletion runs, but the decrease was more pronounced $(P<0.05)$ after the race run. Even 6 days after the half-marathon race, at the end of the loading phase, the free-testosterone concentrations were still significantly lower than the pre-run values. In five out of six subjects, the serum cortisol concentrations were higher after the race than those obtained after the fartlek. This difference did not reach statistical significance.

\section{Discussion}

In the present study, neither the race nor the fartlek procedure resulted in clearly increased glycogen concentrations in the subjects. In addition, no differences in final muscle glycogen levels between

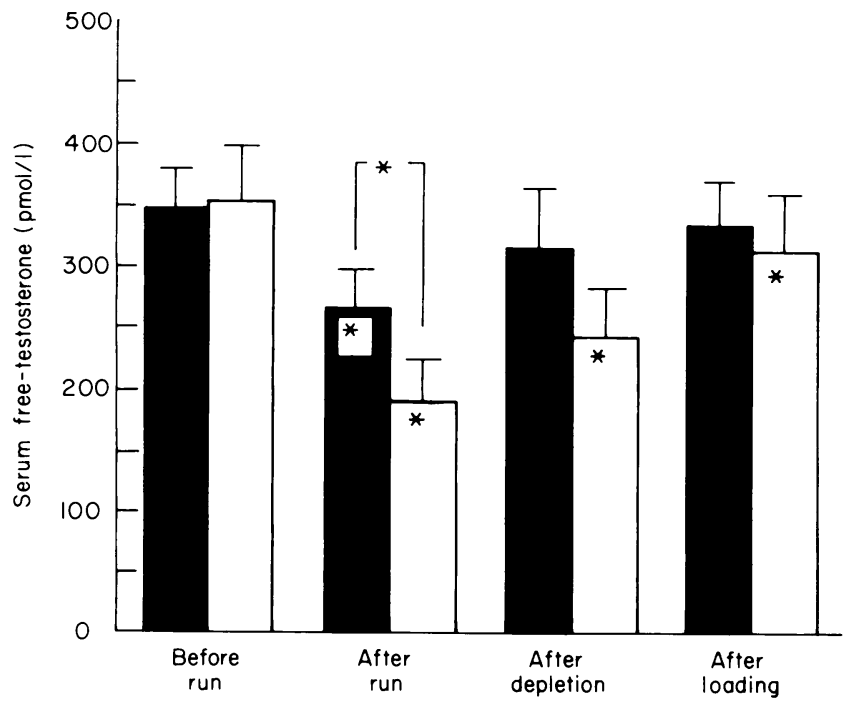

Figure 2. Serum free-testosterone concentration during two glycogen depletion and loading procedures in six male runners. The procedures differed in the depletion run which was either hard (race) or moderate (fartlek). The results are expressed as mean \pm s.e.m. Significant differences $(P<0.05)$ between the procedures and the changes from pre-run values are denoted with an asterisk. $\square$, Moderate run; $\square$, hard run

the procedures were observed. The failure to demonstrate an increase in glycogen concentration following either experiment was rather surprising, since these kinds of procedures are commonly carried out by marathon runners in Finland. It seems that higher glycogen concentrations, in the vastus lateralis muscle, do not necessarily occur after carbohydrateloading procedures in field conditions. Hence, the results agree well with the laboratory studies carried out by Blom et al. ${ }^{7}$.

We admit that the easy runs, performed daily by all subjects during the loading phase, may be one reason why much higher muscle glycogen concentrations did not occur ${ }^{19}$. However, we did not want the subjects to rest because, in practice, marathon runners often perform easy exercises during the loading phase. A study to compare glycogen levels after complete rest and after easy running during the loading phase would be interesting.

The muscle biopsies in the present study were taken from the vastus lateralis muscle, because we were familiar with the technique. It is possible that glycogen synthesis occurs more readily in the gastrocnemius muscle ${ }^{20}$. On the other hand, Karlsson and Saltin ${ }^{21}$ found increased glycogen levels in the vastus lateralis after a carbohydrate-loading regimen. Moreover, in the study of Blom et al. ${ }^{7}$, the results (normal glycogen concentrations, despite carbohydrate loading) were the same as ours, although they used biopsies taken from the gastrocnemius muscle. They also theorized that muscle fibre damage, sometimes associated with prolonged running 22 , might interfere with glycogen resynthesis.

We doubt that the diets unduly influenced the above findings. We did not use a strict fat and protein diet during the depletion phase, but this should not 
impede glycogen resynthesis ${ }^{23}$. The carbohydrate intake, about $600 \mathrm{~g}$ /day during the fartlek and race procedures, should have been high enough to ensure a maximal rate of glycogen synthesis ${ }^{6}$. Moreover, $40 \%$ of total carbohydrate was derived from wholegrain cereals, which contain a lot of complex carbohydrates. Complex carbohydrates might even stimulate glycogen resynthesis more effectively than mono- or disaccharides ${ }^{3}$. In other studies, a lower intake of carbohydrate has resulted in clearly increased glycogen concentrations in the vastus lateralis muscle ${ }^{3,5,21,23}$.

All the subjects felt that the fartlek run was much less exhausting than the race. This subjective feeling of fatigue after the intense run was confirmed by hormonal analyses: serum testosterone and free testosterone concentration decreased after the intense run, which is in agreement with Dessypris et al. ${ }^{24}$ and Kuoppasalmi et al. ${ }^{9}$. Increased serum cortisol values, observed in five out of six subjects after the intense run, further indicated heavy physical strain.

It can be conjectured that the low concentrations of free testosterone throughout the loading phase after the race impaired glycogen resynthesis. In rats, low serum testosterone concentrations may cause a reduction in glycogen synthesis ${ }^{10,25}$. However, it is not known whether this occurs in man as well.

In conclusion, we studied a total of 12 glycogen depletion and loading procedures in six athletes in field conditions, and only five out of 12 resulted in higher glycogen concentrations in the vastus lateralis muscle after rather than before the procedure. Different depletion runs did not affect post-loading glycogen levels. Since an exhaustive depletion exercise might lead to physical overstrain, we do not recommend it for marathon runners.

\section{Acknowledgements}

This study was supported financially by the Finnish Olympic Committee. We also thank Ms Sirpa Tamminen and Ms Helena Taskinen for their skillful technical assistance.

\section{References}

1 Bergström J, Hermansen L, Hultman E, Saltin B. Diet, muscle glycogen and physical performance. Acta Physiol Scand 1967; 71: $140-50$.

2 Saltin B, Hermansen L. Glycogen stores and prolonged severe exercise. In: Blix G, ed. Symposia of the Swedish Nutrition Foundation V: Nutrition and Physical Activity. Stockholm: Almqvist \& Wiksell, 1967.

3 Costill DL, Sherman WM, Fink WJ, Maresh C, Witten M, Miller JM. The role of dietary carbohydrates in muscle glycogen resynthesis after strenuous running. Am J Clin Nutr 1981; 34: 1831-6.

4 Sherman WM, Costill DL, Fink WJ, Hagerman FC, Armstrong LE, Murray TF. Effect of a $42.4-\mathrm{km}$ footrace and subsequent rest or exercise on muscle glycogen and enzymes. J Appl Physiol 1983; 55: 1218-24.

5 Roberts KM, Noble EG, Hayden DB, Taylor AW. Simple and complex carbohydrate-rich diets and muscle glycogen content of marathon runners. Eur J Appl Physiol 1988; 57: 70-4.

6 Sherman WM, Costill DL. The marathon: dietary manipulation to optimize performance. Am J Sports Med 1984; 12: 44-51.

7 Blom PCS, Costill DL, Vollestad NK. Exhaustive running: inappropriate as a stimulus of muscle glycogen supercompensation. Med Sci Sports Exerc 1987; 19: 398-403.

8 Adlercreutz $\mathrm{H}$, Härkönen $\mathrm{M}$, Kuoppasalmi $\mathrm{K}$ et al. Effect of training on plasma anabolic and catabolic steroid hormones and their response during physical exercise. Int J Sports Med 1986; 7 Suppl: $27-8$.

9 Kuoppasalmi $K$, Näveri $H$, Härkönen $M$, Adlercreutz $H$. Plasma cortisol, androstenedione, testosterone and luteinizing hormone in running exercise of different intensities. Scand $J$ Clin Lab Invest 1980; 40: 403-9.

10 Urhausen A, Kullmer T, Kinderman W. A 7-week follow-up study of the behaviour of testosterone and cortisol during the competition period in rowers. Eur J Appl Physiol 1987; 56: 528-33.

11 Fogelholm GM, Tikkanen HO, Näveri, HK, Härkönen MHA. High-carbohydrate diet for long distance runners - a practical view-point. Br J Sports Med 1989; 23: 94-6.

12 Ahlström A, Räsänen L, Kuvaja K. A method of data processing for food consumption surveys. Ann Acad Sci Fenn [A] IV. 1972; 194: 1-8.

13 Hämäläinen $E$, Tikkanen $H$, Härkönen $M$, Näveri $H$ Adlercreutz $\mathrm{H}$. Serum lipoproteins and sex hormone binding globulin in middle-aged men of different physical fitness and risk of coronary heart disease. Atherosclerosis 1987; 67: 155-62.

14 Anderson $\mathrm{D}$. The role of sex hormone binding globulin in health and disease In: James VHT, Serio M, Giusti G, eds. The Endocrine Function of the Human Ovary. Proceedings of the Serono Symposia Vol. 7. London: Academic Press, 1976.

15 Rehunen S, Härkönen MHA. High-energy phosphate compounds in human slow-twitch and fast-twitch muscle fibres. Scand J Clin Lab Invest 1980; 40: 45-54.

16 Good CA, Kramer H, Somogyi M. The determination of glycogen. J Biol Chem 1933; 100: 485-91.

17 Härkönen $M$, Näveri $H$, Rehunen $S$, Kuoppasalmi $K$ Determination of metabolites and enzymes in muscle. Ann Clin Res 1982; 14 (Suppl. 34): 20-4.

18 Langley RL. Practical Statistics. London: Pan Books, 1979.

19 Bonen A, Ness GW, Belcastro AN, Kirby RL. Mild exercise impedes glycogen repletion in muscle. J Appl Physiol 1985; 58: 1622-9.

20 Costill DL, Jansson E, Gollnick PD, Saltin B. Glycogen utilization in leg muscles of men during level and uphill running. Acta Physiol Scand 1974; 91: 475-81.

21 Karlsson J, Saltin B. Diet, muscle glycogen, and endurance performance. I Appl Physiol 1971; 31: 203-6.

22 Hikida RS, Staron RS, Hagerman FC, Sherman WM, Costill DL. Muscle fiber necrosis associated with human marathon runners. J Neurol Sci 1983; 59: 185-203.

23 Sherman WM, Costill DL, Fink WJ, Miller JM. Effect of exercise-diet manipulation on muscle glycogen and its subsequent utilization during performance. Int J Sports Med 1981; 2: 114-8.

24 Dessypris A, Kuoppasalmi K, Adlercreutz H. Plasma cortisol, testosterone, androstenedione and luteinizing hormone ( $\mathrm{LH})$ in a non-competitive marathon run. J Steroid Biochem 1976; 7: 33-7.

25 Guezennec CV, Ferre P, Serrurier DB, Merino D, Pesquies PC. Effects of prolonged physical exercise and fasting upon plasma testosterone level in rats. Eur J Appl Physiol 1982; 49: $159-68$. 